\title{
M.C.V. should not be the only criteria to order vitamin B12 for anemia under evaluation
}

\author{
Rohit Jain, Menka Kapil, Gajendra Nath Gupta \\ Department of Pathology \& Transfusion Medicine, Santokba Durlabhji Memorial Hospital, Jaipur, India \\ Email: funkyaarjay@yahoo.com
}

Received 23 April 2012; revised 13 July 2012; accepted 30 July 2012

\begin{abstract}
Introduction: A strict vegetarian diet has been associated with increased risk of cobalamin deficiency therefore; one would expect a high prevalence of Cobalamin deficiency in India. Erythrocyte indices have been used in the initial evaluation of anemic patients; high Mean corpuscular volume (MCV) is a traditional criterion for folate and vitamin B12 deficiencies. There is no large study of the prevalence of B12 deficiency among patients with normocytosis or microcytosis. Method: We retrospectively analyzed the records of serum vitamin B12 and MCV of both inpatients and outpatients at Santokba Durlabhji Memorial Hospital \& Research Institute, Jaipur (Rajasthan) during the period from August 2010-April 2011. The study was aimed at identifying the correlation between vitamin B12 level and MCV; and prevalence of vitamin B12 deficiency in this region. Result \& Conclusion: Every third person is vitamin B12 deficient in the region. There is no correlation between vitamin B12 levels and MCV in majority of the cases. MCV should not be the only criteria for ordering vitamin B12 for patients with anemia under evaluation.
\end{abstract}

Keywords: Vitamin B12; MCV; Deficiency; Prevalence; Investigation

\section{INTRODUCTION}

Attempts to unravel the mystery of Anemia dates back to almost two centuries. During this period combe [1], Thomas Addison [2], Austin Flint [3] and Wiliam Castle [4] made important contributions in this field. A substantial population of India adheres to a vegetarian diet for cultural and religious reasons. A vegetarian diet is considered to promote health and longevity by protecting against conditions such as cardiovascular disease (CVD) and cancer [5], however this diet may be deficient in some nutrients [6,7]. In particular a strict vegetarian diet has been associated with increased risk of Cobalamin deficiency $[7,8]$. Malnutrition is common in India [9] and tropical sprue, gastrointestinal infections, and other nutrient deficiencies frequently result in a malabsorptive state $[10,11]$. Therefore, one would expect a high prevalence of Cobalamin deficiency in India. Indeed, reports from both India [12,13] and studies of Indians living in other countries $[14,15]$ suggest that nutritional Cobalamin deficiency is common. A recent report shows $46.9 \%$ of non-anemic adult subjects having subnormal levels of $\mathrm{B}_{12}$ or Folate- $\mathrm{B}_{12}$ deficiency being five times more common than folate [16]. Another study showed $60 \%$ of vegetarians and $39 \%$ of nonvegetarians were B12 deficient [17]. Classic Cobalamin deficiency is associated with megaloblastic anemia and neurologic symptoms [18]. Measurement of serum Cobalamin is the most commonly used biochemical test for diagnosing Cobalamin deficiency $[19,20]$. Erythrocyte indices have been used in the initial evaluation of anemic patients; high Mean corpuscular volume (MCV) value is a traditional criterion for folate and vitamin B12 deficiencies [21]. There is no large study of the prevalence of B12 deficiency among patients with normocytosis or microcytosis. Our study was aimed at identifying the correlation between vitamin B12 level and MCV and prevalence of vitamin B12 deficiency in this region.

\section{MATERIAL AND METHODS}

We retrospectively analyzed the records of serum vitamin B12 and MCV of both inpatients and outpatients at Santokba Durlabhji Memorial Hospital \& Research Institute, Jaipur (Rajasthan) during the period from August 2010-April 2011. The serum vitamin B12 levels were determined by competitive binding Immunoassay on VITROS 3600 Immunodiagnostic System based on enhanced Chemiluminescence, Ortho Clinical Diagnostics, USA which quantitatively measures B12 concentration in human serum and plasma (EDTA or Heparin) to aid the differential diagnosis of anemia. Biological Reference Interval of vitamin B12 levels was $239-931 \mathrm{pg} / \mathrm{mL}$. MCV was measured by Sysmex-1800-xi from EDTA sample (Normal Range 80 - $100 \mathrm{fL}$ ). Quality assurance in all tests was maintained as per National standards. We 
categorized the vitamin B12 results in four groups ranging from <100, 100 - 239, 240 - 499 and 500 - 1000 $\mathrm{pg} / \mathrm{mL}$. The MCV was sorted for each group using MS office Excel 2007 and the mean MCV was established for all the four groups.

\section{RESULTS}

During the Nine month period of study we investigated a total number of 2388 serum vitamin B12 level with corresponding MCV values. The seroprevalence of vitamin B12 deficiency is $36.5 \%$. The results reveal that vitamin B12 deficiency would increase MCV (Table 1).

Out of 868 patients who were vitamin B12 deficient 10.36\% had high MCV (>100 fL). 13.13\% had low MCV $(<80 \mathrm{fL})$ and $76.49 \%$ were with normal values of MCV (80 - $100 \mathrm{fL}$ ) (Table 2).

Out of 1520 patients with normal vitamin B12 level 23.81\% had low MCV and 3.48\% had high MCV and 72.69\% were with normal value of MCV (Table 3).

\section{DISCUSSION}

The most notable finding is every third person is Vitamin B12 deficient in this region in concordance with study by Kankonkar et al. in 2004 [22]. The population of the Indian subcontinent is $>1$ billion, most of whom consume a diet low in Cobalamin. Isolated reports suggest that Cobalamin deficiency in India is common; however, this problem has received little attention. The national stra-

Table 1. Correlation of vitamin B12 and MCV with distribution of patients.

\begin{tabular}{cccc}
\hline & Vit. B12 (pg/mL) & \% of Patients & Mean MCV (fL) \\
\hline 1 & $<100 \mathrm{pg} / \mathrm{mL}$ & 0.8 & 103.8 \\
2 & $100-239 \mathrm{pg} / \mathrm{mL}$ & 35.7 & 87.3 \\
3 & $240-499 \mathrm{pg} / \mathrm{mL}$ & 39 & 85.1 \\
4 & $500-1000 \mathrm{pg} / \mathrm{mL}$ & 24.5 & 85.8 \\
\hline
\end{tabular}

Table 2. MCV distribution in patients with low vitamin B12 levels $(\mathrm{n}=868)$.

\begin{tabular}{ccc}
\hline \multicolumn{3}{c}{ No. of Patients } \\
\hline Low MCV & Normal MCV & High MCV \\
114 & 664 & 90 \\
\hline
\end{tabular}

Table 3. MCV distribution in patients with normal vitamin B12 levels $(\mathrm{n}=1520)$.

\begin{tabular}{ccc}
\hline \multicolumn{3}{c}{ No. of Patients } \\
\hline Low MCV & Normal MCV & High MCV \\
362 & 1105 & 53 \\
\hline
\end{tabular}

tegies for improving micronutrient intake do not include Cobalamin [20]. In 1934 Wintrobe published synthesis of Red Cell Measurement for diagnosis and classification of Anemia. This classification was based on derived Red Cell Indices. Erythrocyte Indices have been used in initial evaluation of Anemia patients, High MCV values is traditional criteria for B12 and folate deficiency [23]. Wheeler et al. suggested that vitamin B12 should be determined in Anemia patients when MCV > $100 \mathrm{fL}$ [24]. Our study also proves inverse relationship of MCV with vitamin B12 deficiency as P. Vant Sant et al. [25], Oosterheris et al. [26], Mahmoud A. Fora et al. [27] did in their respective studies.

We found several interesting observations during our study in which traditional criteria of vitamin B12 and MCV association was not followed in half of the cases. Among 2388 patients only 6\% had macrocytosis, 20\% had microcytosis and 74\% were normocytic. These findings suggest that concomitant iron or other nutritional deficiencies or hemoglobinopathies [21,28,29] may have been responsible for the normal or even low MCV values in some of our anemic patients; such anemias and hemoglobinopathies have been seen commonly in Southeast Asians [21,30-32]. Moreover, the combination in anemia has been reported in the literature [33-35]. Thompson et al. reported that $82 \%$ of patients with low B12 levels seen at Bellevue Hospital, New York, had MCV values below $95 \mathrm{fL}$; they suggested that further evaluation of the suspected B12 deficiency should not be deterred by a normal MCV value which is one of the important observation in our study [36].

One study from Vancuover AIDS conference (1996) suggested that MCV does not always get high even if vitamin B12 is low so a normal value does not necessaryily means that B12 levels is normal, which correlates with our findings. Thus physicians should not consider elevated MCV as diagnostic criteria for Vitamin B12 deficiency $[17,26,37,38]$. Oosterhuis et al. analyzed the diagnostic value of an elevated MCV for B12 deficiency where the sensitivity was only $17 \%-30 \%$, and up to $84 \%$ of the deficiency would be missed [26]. Any screening criteria selected would miss a significant number of B12 deficient patients, so there may be a case for universal B12 screening [39].

\section{LIMITATIONS}

Our study has some important limitations. First, dietary information was not available. Second, our study was based on serum B12 results, which alone, without other biochemical markers such as Homocysteine, Methymalonic acid might not be an accurate measures of B12 deficiency [20]. Even if our findings are valid, we must consider their clinical significance. We believe that B12 
deficiency is not just a laboratory finding but a clinically relevant issue as the symptoms are vague and nonspecific but respond to appropriate Vitamin B12 therapy.

\section{CONCLUSION}

Every third person is vitamin B12 deficient in the region. There is no correlation between vitamin B12 levels and MCV in majority of the cases. MCV should not be the only criteria for ordering vitamin B12 for patients with anemia under evaluation.

\section{REFERENCES}

[1] Combe, J.S. (1824) History of a case of anaemia. Transactions Royal Medical \& Chirurgical Society Edinburgh, 7, 194-203.

[2] Addison, T. (1980) On the constitutional and local effects of disease of the suprarenal capsule. In: Goodhart, R.S. and Shils, M.E., Eds., Modern Nutrition in Health and Disease, 6th Edition, 229-259.

[3] Flint, A. (1860) A clinical lecture on anemia. American Medical Times, 1, 181-186.

[4] Castle, W.B. (1929) Nutrition classics. The American Journal of the Medical Science, 178, 748-764. doi:10.1097/00000441-192912000-00002

[5] Appleby, P.N., Thorogood, M., Mann, J.I. and Key, T.J. (1999) The Oxford vegetarian study: An overview. The American Journal of Clinical Nutrition, 70, 525S-531S.

[6] Laidlaw, S.A., Shultz, T.D., Cecchino, J.T. and Kopple, J.D. (1988) Plasma and urine taurine levels in vegans. The American Journal of Clinical Nutrition, 47, 660-663.

[7] Sanders, T.A. (1999) The nutritional adequacy of plantbased diets. Proceedings of the Nutrition Society, 58, 265-269. doi:10.1017/S0029665199000361

[8] Herbert, V. (1994) Staging vitamin B-12 (Cobalamin) status in vegetarians. The American Journal of Clinical Nutrition, 59, 1213S-1222S.

[9] Balaji, L.N. and Dustagheer, A. (2000) Nutrition scenario in India-Implications for clinical practice. Journal of the Indian Medical Association, 98, 536-538, 542.

[10] Mathan, V.I. (1988) Tropical sprue in Southern India. Transactions of the Royal Society of Tropical Medicine and Hygiene, 82, 10-14. doi:10.1016/0035-9203(88)90247-7

[11] Herbert, V. (1985) Biology of disease: Megaloblastic anemias. Laboratiry Investigation, 52, 3-19.

[12] Kumar, S., Ghosh, K. and Das, K.C. (1989) Serum vitamin $B_{12}$ levels in an Indian population: An evaluation of three assay methods. Medical Laboratory Science, 46, 120-126.

[13] Gomber, S., Kumar, S., Rusia, U., Gupta, P., Agarwal, K.N. and Sharma, S. (1998) Prevalence and etiology of nutritional anaemias in early childhood in an urban slum. Indian Journal of Medical Research, 107, 269-273.

[14] Ng, S.C., Kuperan, P., Chan, K.S., Bosco, J. and Chan,
G.L. (1988) Megaloblastic anaemia-A review from University Hospital, Kuala Lumpur. Annals, Academy of Medicine, Singapore, 17, 261-266.

[15] Chanarin, I., Malkowska, V., O’Hea, A.M., Rinsler, M.G. and Price, A.B. (1985) Megaloblastic anaemia in a vegetarian Hindu community. Lancet, 2, 1168-1172. doi:10.1016/S0140-6736(85)92690-X

[16] Khanduri, U., Sharma, A. and Joshi, A. (2005) Occult Cobalamin and folate deficiency in Indians. National Medical Journal of India, 18, 182-183.

[17] Anil, K.G., Damji, A. and Uppaluri, A. (2004) Vitamin B12 deficiency prevalence among south Asians at a Toronto clinic. Canadian Family Physician, 50, 743-747.

[18] Scott, J.M. (1999) Folate and vitamin $B_{12}$. Proceedings of the Nutrition Society, 58, 441-448. doi:10.1017/S0029665199000580

[19] Lindenbaum, J., Savage, D.G., Stabler, S.P. and Allen, R.H. (1990) Diagnosis of Cobalamin deficiency. II. Relative sensitivities of serum Cobalamin, methylmalonic acid and total homocysteine concentrations. American Journal of Hematology, 34, 99-107. doi:10.1002/ajh.2830340205

[20] Refsum, H., Yajnik, C.S., Gadkari, M., Schneede, J., Vollset, S.E., Örning, L., Guttormsen, A.B., Joglekar, A., Sayyad, M.G., Ulvik A. and Ueland, P.M. (2001) Hyperhomocysteinemia and elevated methylmalonic acid indicate a high prevalence of Cobalamin deficiency in Asian Indians. The American Journal of Clinical Nutrition, $\mathbf{7 4}$ 233-241.

[21] Quoc Luong, K.V. and Hoang Nguyen, L.T. (2000) Folate and vitamin B12 deficiency Anemias in Vietnamese immigrants living in Southern California. Southern Medical Journal, 93, 53-57.

[22] Kankonkar, S.R., Joshi, S.V., Tijoriwala, S.J., Prabhu, R.V., Raikar, S.C., Kankonkar, R.C. and Dhar, H.L. (2004) A study of vitamin B12 deficiency in different diseases. Bombay Hospital Journal, 46.

[23] Wintrobe, M.M. (1943) Anemia-Classification and treatment on the basis of differences in the average value and hemoglobin content of the red corpuscles. Archives of Internal Medicine, 54, 256-280. doi:10.1001/archinte.1934.00160140099006

[24] Wheeler, L.A., Brecher, G. and Sheiner, L.B. (1977) Clinical laboratory use in the evaluation of anemia. The Journal of the American Medical Association, 238, 27092714. doi:10.1001/jama.1977.03280260039014

[25] Vant Sant, P., Küsters, P.F. and Harthoorn-Lasthuizen, E.J. (1997) Dependency of MCV and haemoglobin concentration on plasma vitamin B12 levels in relation to sex and age. Clinical and Laboratory Haematology, 19, 2731. doi:10.1046/j.1365-2257.1997.00214.X

[26] Oosterhuis, W.P., Niessen, R.W., Bossuyt, P.M., Sanders, G.T. and Sturk, A. (2000) Diagnostic value of mean corpuscular volume in the detection of vitamin B12 deficiency. Scandinavian Journal of Clinical \& Laboratory Investigation, 60, 9. doi:10.1080/00365510050184994

[27] Fora, M.A. and Mohammad, M.A. (2005) High frequency of suboptimal serum vitamin B12 level in adults in Jordan. Saudi Medical Journal, 26, 1591-1595. 
[28] Aslinia, F., Mazza, J.J. and Yale, S.H. (2006) Megaloblastic anemia and other causes of macrocytosis. Clinical Medicine \& Research, 4, 236-241. doi:10.3121/cmr.4.3.236

[29] Obeid, R., Geisel, J., Schorr, H., Hübner, U. and Herrmann, W. (2002) The impact of vegetarianism on some haematolgical paramaters. European Journal of Haematology, 69, 275-279. doi:10.1034/j.1600-0609.2002.02798.x

[30] Fairbanks, V.F., Gilchrist, G.S., Brimhall, B., Jereb, J.A. and Goldston, E.C. (1979) Hemoglobin E trait reexamined: A cause of microcytosis and erythrocytosis. Blood, 53, 109-115.

[31] Hurst, D., Tittle, B., Kleman, K.M., Embury, S.H. and Lubin, B.H. (1983) Anemia and hemoglobinopathies in Southeast Asian refugee children. Journal of Pediatrics, 102, 692-697. doi:10.1016/S0022-3476(83)80235-2

[32] Dode, C., Berth, A., Bourdillon, F., Mahe, C., Labie, D. and Rochette, J. (1987) Haemoglobin disorders among Southeast-Asian refugees in France. Acta Haematologica, 78, 135-136. doi:10.1159/000205862

[33] Croft, R.F., Streeter, A.M. and O’Neill, B.J. (1974) Red cell indices in megaloblastosis and iron deficiency. $\mathrm{Pa}$ thology, 6, 107-117. doi:10.3109/00313027409068973

[34] Spivak, J.L. (1982) Masked megaloblastic anemia. Archives of Internal Medicine, 142, 2111-2114. doi:10.1001/archinte.1982.00340250071012

[35] Green, R., Kuhl, W., Jacobson, R., Johnson, C., Carmel, R. and Beutler, E. (1982) Masking of macrocytosis by alpha-thalassemia in blacks with pernicious anemia. The New England Journal of Medicine, 307, 1322-1325. doi:10.1056/NEJM198211183072106

[36] Thompson, W.G., Babitz, L., Cassino, C., Freedman, M. and Lipkin, M., Jr. (1987) Evaluation of current criteria used to measure vitamin $\mathrm{B}_{12}$ levels. American Journal of Medicine, 82, 291-294. doi:10.1016/0002-9343(87)90070-2

[37] Tang, A.M. (1996) The role of serum micronutrient levels in HIV-1 disease progression. Johns Hopkins University, Baltimore.

[38] den Elzen, W.P.J., van der Weele, G.M., Gussekloo, J., Westendorp, R.G.J. and Assendelft, W.J.J. (2010) Subnormal vitamin B12 concentrations and anaemia in older people: a systematic review. BMC Geriatrics, 10, 42. doi:10.1186/1471-2318-10-42

[39] Chui, C.H., Lau, F.Y., Wong, R., Soo, O.Y., Lam, C.K., Lee, P.W., Leung, H.K., So, C.K., Tsoi, W.C., Tang, N., Lam, W.K. and Cheng, G. (2001) Vitamin B12 deficiencyNeed for a new guideline. Applied Nutritional Investigation, 17, 917-920. 